\title{
A CLINICO-EPIDEMIOLOGICAL STUDY OF INFERTILE COUPLES AMONG THE SUBURBAN/RURAL POPULATION OF BOKAKHAT, ASSAM
}

\author{
Pranabika Mahanta ${ }^{1}$
}

${ }^{1}$ Assistant Professor, Department of Obstetrics and Gynaecology, Jorhat Medical College \& Hospital, Nandanpur.

\begin{abstract}
Infertility is a disease of the reproductive system defined by the failure to achieve a clinical pregnancy after 12 months or more of regular unprotected sexual intercourse (WHO-ICMART). Infertility is the inability of a sexually active, non-contraception couple to achieve pregnancy in one year. Infertility affects relatively large number of couples, both globally as well as in India. There are sparse data on the prevalence of infertility in India. This study describes the correlates and prevalence of infertility among couples in Bokakhat, Assam, India.
\end{abstract}

\section{MATERIALS AND METHODS}

This study is a cross-sectional study done in the suburban/rural field practice area of Bokakhat Subdivisional Civil Hospital, during August 2008 to July 2009. Couples having infertility were identified using WHO definition by house to house survey and interviewed to know various epidemiological correlates including demographic characteristics, aetiology and treatment if taken for the same.

\section{RESULTS}

There were total of 1755 eligible couples and 167 were found to be having primary or secondary infertility. The study showed that among eligible couple's prevalence of primary infertility was $6.4 \%$, while secondary infertility was $3.01 \%$. Among couples with primary infertility, male factors were responsible in 18 (15.78\%), female factors in $32(28.07 \%)$, both partners were accountable in 27 (23.68\%), while 37 (32.45\%) couple's cause of infertility was unexplained.

\section{CONCLUSION}

It was concluded that this study has provided significant information concerning the prevalence of infertility in our area and also provided information about different demographical and aetiological factors associated with infertility.

\section{KEYWORDS}

Primary Infertility, Secondary Infertility, Eligible Couple.

HOW TO CITE THIS ARTICLE: Mahanta P. A clinico-epidemiological study of infertile couples among the suburban/rural population of Bokakhat, Assam. J. Evolution Med. Dent. Sci. 2016;5(24):1296-1299, DOI: 10.14260/jemds/2016/303

\section{INTRODUCTION}

Infertility is not merely a health problem; it is also a matter of social injustice and inequality. ${ }^{1}$ Infertility can have a serious impact on both the psychological well-being and the social status of women in the developing world. As a result of their infertile status they suffer physical and mental abuse, neglect, abandonment, economic deprivation and social ostracism as well as exclusion from certain social activities and traditional ceremonies. ${ }^{1}$ Infertility is a disease of the reproductive system defined by the failure to achieve a clinical pregnancy after 12 months or more of regular unprotected sexual intercourse (WHO-ICMART). Infertility is the inability of a sexually active, non-contraception couple to achieve pregnancy in one year. ${ }^{2}$ Infertility is a global health issue, affecting approximately $8-10 \%$ couples worldwide. ${ }^{2}$ The World Health Organization (WHO) estimates that 60 to 80 million couples worldwide currently suffer from infertility. ${ }^{2}$ The WHO estimates of primary infertility in India are 3.9\% (Age-standardized to 25-49 yr.) and 16.8\% (Age-standardized to $15-49$ yr.) using the "Age but no birth" definition.

Financial or Other, Competing Interest: None.

Submission 30-01-2016, Peer Review 04-03-2016,

Acceptance 11-03-2016, Published 23-03-2016.

Corresponding Author:

Dr. Pranabika Mahanta,

Nandanpur, Jail Road,

Jorhat-785001, Assam.

E-mail: pranabikamgoswami@gmail.com

DOI: $10.14260 /$ jemds $/ 2016 / 303$
As per study published at the end of 2012 by WHO, one in every four couples in developing countries had been found to be affected by infertility. ${ }^{3}$ The magnitude of the problem calls for urgent action, particularly when in the majority of cases the infertility is avoidable. Estimates of infertility vary widely among Indian states from $3.7 \%$ in Uttar Pradesh, Himachal Pradesh and Maharashtra to 5\% in Andhra Pradesh and $15 \%$ in Kashmir.4,5,6

Infertility is divided into primary and secondary infertility. WHO defines primary infertility as the inability to conceive within one year of exposure to pregnancy (i.e. sexually active, non-contracepting and non-lactating) among women 15 to $49 \mathrm{yr}$. old. Secondary infertility refers to the inability to conceive following a previous pregnancy.7 The female factors contribute almost half in the aetiologies of infertility followed by male factors $(30-40 \%)$ and the rest are attributed to a mixture of both or by problems unknown. ${ }^{8}$ The biological and social factors including stress due to economic status, religious attitudes, age at marriage, urbanization leading to modernization, higher literacy, contraceptive usage and nuclear families play a significant role in lowering fertility. ${ }^{9}$ Sexually Transmitted Infections (STIs) are generally considered the leading preventable cause of infertility worldwide, especially in developing countries. ${ }^{10}$

Although, identifying the cause of infertility may not bring hope to the infertile couples in a developing country like India where cost of investigation or treatment is not affordable by majority. But identifying the cause may give relief to the 
women from various social stigmas where women are blamed or made entirely responsible for her bare womb. So the purpose of the study is to identify and quantify some demographic factors and causes, correlates and prevalence of infertility among couples in Bokakhat area. Bokakhat is a subdivision of Golaghat district of Assam, India. The population in this area mostly resides in suburban and rural areas and also a large number of people reside in the vicinity of forest.

\section{MATERIAL AND METHOD}

This study is a cross-sectional study done in the rural field practice area of Bokakhat Subdivisional Civil Hospital, during August 2008 to July 2009. Couples having infertility were identified using WHO definition. Cases who attended gynaecological outpatient department with h/o inability to conceive were interviewed to know various clinicoepidemiological correlates including demographic characteristics, aetiology and treatment if taken for the same. Asha workers were trained to interview the female counterparts of the couples about the fertility status and asked to bring the infertile couples to the Subdivisional Civil Hospital, where I was previously working. Couples having infertility were identified using WHO definition by house to house survey and interviewed to know various epidemiological correlates including demographic characteristics, aetiology and treatment if taken for the same. There were total of 1230 eligible couples and 190 were found to be having primary or secondary infertility. Females eligible for the study were interviewed as per the pre-structured questionnaire after taking their consent to participate. Females who could not be contacted during first visit were revisited. Those who were not available during 2nd visit were excluded along with who refused to participate; 23 number of couples either refused investigation or has not reported for second visit were excluded from the study. So total number of study population turned out to be 167 .

\section{RESULTS}

In our study out of 1755 eligible couples 190 (10.82\%) were found to be infertile; 167 couples were included as 23 number of couples were not available even during 2 nd visit. Majority of husbands were in 36-40 years' age group (34.1\%) and while majority of wives were in $31-35$ years' $(40.1 \%)$ age group (Table 1). The study showed that among the infertile couples prevalence of primary infertility was 114 (6.4\%), while secondary infertility was 53 (3.01\%) (Table 2). Primary infertility was most prevalent in middle income group (37.12\%), secondary infertility was most prevalent in low income group (59.28\%) (Table 3). Both types of infertility is common in persons married after 30 (Table 3). Among couples with primary infertility, male factors were responsible in 18 (15.78\%), female factors in 32 (28.07\%), both partners were accountable in 27 (23.68\%), while 37 (32.45\%) couples cause of infertility was unexplained (Table 4). Among couples with secondary infertility, male factors were responsible in 35 (66.03\%), female factors in 35 (66.03\%), both partners were accountable in $8(15.09 \%)$, while $4(7.5 \%)$ couples cause of infertility was unexplained (Table 4). It was concluded that this study has provided significant information concerning the prevalence of infertility in this area and has informed about different demographical and etiological factors associated with infertility (Table 5) shows that out of total 167 couples only 40 couples accepted they had earlier received any treatment; $47.05 \%$ secondary infertility couples had approached for treatment of infertility, while only $27.47 \%$ of couples with primary infertility received any treatment before the study. As per the records available at the time of visit 22 couples with primary infertility got only their basic investigations done but did not receive any treatment, while 15 patients had already received medical treatment and only 2 couples were surgically treated for infertility. While in secondary infertility group 18 couples were investigated earlier for infertility, 10 were already taking medical treatment and 4 had undergone hydrotubation/hysteroscopic septal resection surgery for infertility treatment.

\begin{tabular}{|c|c|c|c|c|}
\hline Age & Husband & $\mathbf{\%}$ & Wife & \% \\
\hline $21-25$ & 7 & 4.1 & 3 & 1.7 \\
\hline $26-30$ & 15 & 8.9 & 28 & 16.7 \\
\hline $31-35$ & 48 & 28.7 & 67 & 40.1 \\
\hline $36-40$ & 57 & 34.1 & 53 & 31.7 \\
\hline $41-45$ & 33 & 19.76 & 16 & 9.5 \\
\hline$>45$ & 7 & 4.1 & 0 & 0 \\
\hline $\begin{array}{c}\text { Educational } \\
\text { status }\end{array}$ & & & & \\
\hline Post Graduate & 11 & 6.5 & 4 & 2.3 \\
\hline Graduate & 23 & 13.77 & 17 & 10.17 \\
\hline $\begin{array}{c}\text { Intermediate or } \\
\text { diploma }\end{array}$ & 29 & 17.36 & 26 & 15.56 \\
\hline High school & 43 & 25.74 & 32 & 19.16 \\
\hline Middle school & 29 & 17.36 & 40 & 23.95 \\
\hline Primary school & 11 & 6.5 & 21 & 12.57 \\
\hline Illiterate & 21 & 12.57 & 27 & 16.16 \\
\hline Occupation & & & & \\
\hline Professional & 3 & 1.7 & 1 & .59 \\
\hline Semi professional & 11 & 6.5 & 0 & 0 \\
\hline Clerical or shop & 33 & 19.76 & 17 & 10.17 \\
\hline Skilled worker & 20 & 11.97 & 10 & 5.9 \\
\hline $\begin{array}{c}\text { Semi-skilled } \\
\text { worker }\end{array}$ & 28 & 16.76 & 40 & 23.95 \\
\hline $\begin{array}{c}\text { Unskilled wage } \\
\text { earner }\end{array}$ & 20 & 11.97 & 26 & 15.56 \\
\hline Farmer & 45 & 26.94 & 24 & 14.37 \\
\hline Unemployed & 7 & 4.1 & 49 & 29.34 \\
\hline $\begin{array}{c}\text { Table 1: Distribution of couples with Infertility by } \\
\text { Demographic Characteristics (n=167) }\end{array}$ \\
\hline
\end{tabular}

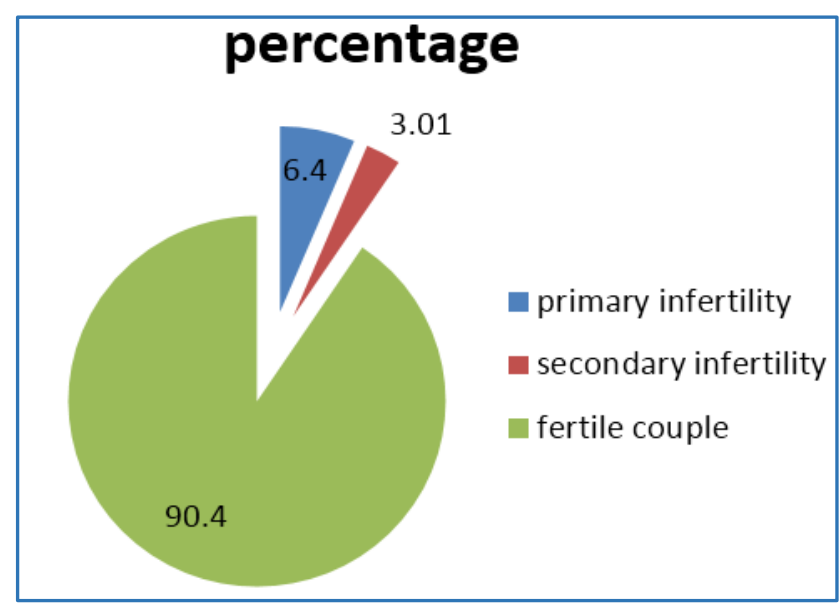

Chart 1: Total 167 Infertile couples out of 1755 Eligible couples 


\begin{tabular}{|c|c|c|}
\hline Socio-economic Status & Primary & Secondary \\
\hline Low & 62 & 99 \\
\hline Middle & 82 & 57 \\
\hline High & 23 & 11 \\
\hline \multicolumn{3}{|l|}{ Age at marriage (wife) } \\
\hline Less than 18 yrs. & 13 & 4 \\
\hline $18-30$ yrs. & 57 & 56 \\
\hline More than 30 yrs. & 97 & 107 \\
\hline \multicolumn{3}{|c|}{$\begin{array}{c}\text { Table 2: Data on Socio-economic Status Age at Marriage } \\
\text { (Wife) and Duration of Infertility }\end{array}$} \\
\hline
\end{tabular}

\begin{tabular}{|c|c|c|}
\hline Causes & Primary & Secondary \\
\hline Male factor & $18(15.78 \%)$ & $35(66.03 \%)$ \\
\hline Female factor & $32(28.07 \%)$ & $35(66.03 \%)$ \\
\hline Unexplained & $37(32.45 \%)$ & $4(7.5 \%)$ \\
\hline $\begin{array}{c}\text { Both } \\
\text { (Male and female factors) }\end{array}$ & $27(23.68 \%)$ & $8(15.09 \%)$ \\
\hline \multicolumn{2}{|c|}{ Table 3: Cause of Infertility } \\
\hline
\end{tabular}

\begin{tabular}{|c|c|c|}
\hline Type of Previous Treatment & Primary & Secondary \\
\hline Only investigations done & 22 & 18 \\
\hline Medical treatment & 15 & 10 \\
\hline Surgical treatment & 2 & 4 \\
\hline \multicolumn{2}{|c|}{ Table 4: Previous Treatment Details } \\
\hline
\end{tabular}

\section{DISCUSSION}

Prevalence of infertility in our study was $10.82 \%$. It is expected that between $8-12 \%$ of couples experience, some forms of infertility thus affecting about 50-80 million people. ${ }^{2}$ The WHO estimates the overall prevalence of primary infertility in India to be between 3.9 and 16.8 percent. ${ }^{4}$ Estimates of infertility vary widely among Indian states. Incidence of primary infertility is $6.4 \%$, which is similar to the findings of Anshu et al., $11.98 \%$ which is similar to the findings of Kumar D1 and Adamson PC.10,11 Prevalence of primary infertility in our study was $6.1 \%$, Chethana R.12 reported $4.5 \%$ prevalence. Mean age of wife's was $33.19+5.46$ (Range: $22-45 \mathrm{yrs}$.), while husband's mean age was 37.5+5.82 (Range: $24-52$ yrs.), which was older than reported by Adamson PC.13 Similar to earlier studies, most of the participants were 31-35 years' age group (33.5\% husbands and $32.4 \%$ wives). Similarly, a survey conducted across 9 cities including 2,562 patients by helping families endorsed by the Indian Society for Assisted Reproduction (ISAR) reported that about $46 \%$ of Indians in the age group of 31 to 40 years seeking medical help for conceiving a child were found to be infertile. ${ }^{14}$ while studies from Indian researchers report lower age for infertility. ${ }^{10,13}$

Although infertility was assumed to be a disease of affluent society, majority of couples suffering with infertility

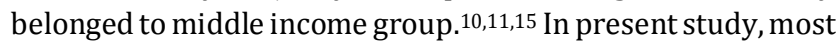
of primary infertility couples were from middle socioeconomic status, which is similar to study conducted by Aflatoonian A et al. ${ }^{13}$ and Anshu et al. ${ }^{16}$ In the present study different underlined causes for primary infertility were male factors 18 (15.78\%), female factors in 32 (28.07\%), both partners were accountable in 27 (23.68\%), while 37 (32.45\%) couples cause of infertility was unexplained is very similar with Anshu et.al.16 where male factors were responsible in 49 (17.95\%), female factors in $86(31.5 \%)$ and both partners were accountable in $66(22.34 \%)$, while $77(28.21 \%)$ couples cause of infertility was unexplained. Among couples with secondary infertility in the present study were male factors responsible in 35 (66.03\%), female factors in 35 (66.03\%), both partners were accountable in $8(15.09 \%)$, while $4(7.5 \%)$ couples cause of infertility was unexplained which is similar with that of Anshu et al. study which concluded that 34 (14.9\%) males had semen abnormalities, female factors were responsible in 136 $(53.33 \%)$ couples and both partners in 44 (17.25\%), while 37 (14.51\%) couples were diagnosed to have unexplained infertility in secondary infertility group.

\section{CONCLUSION}

This study has provided significant information concerning the prevalence of infertility in our area and has informed about different demographical and etiological factors associated with infertility. There is an unreached section of population, who although are suffering from infertility are unaware of the fact that infertility is a disease with possible risk factors and causes which is curable to some extent. Infertility is not a disease of the female, so the couple needs to be interviewed and investigated to find out the cause, specially those residing in rural areas. Efforts are needed to raise awareness of the causes and consequences of infertility among them to address the social aspect of infertility.

\section{REFERENCES}

1. Jumayev I, Rashid MH, Rustamov O, et al. Social correlates of female infertility in uzbekistan. Nagoya J Med Sci 2012;74:273-83.

2. World Health Organization. Infecundity, infertility, and childlessness in developing countries. DHS comparative reports No 9. Calverton, Maryland, USA: ORC Macro and the World Health Organization; 2004.

3. Mascarenhas MN, Flaxman SR, Boerma T, et al. National, regional, and global trends in infertility prevalence since 1990: a systematic analysis of 277 health surveys. PLoS Med 2012;9(12):e1001356.

4. Talwar PP, Go OP, Murali IN. Prevalence of infertility in different population groups in India and its determinants. In: statistics and demography New Delhi: National institute of health \& family welfare \& Indian council of medical research 1986.

5. Unisa S. Childlessness in Andhra Pradesh, India: treatment-seeking and consequences. Reprod Health Matters 1999;7(13):54-65.

6. Zargar AH, Wani AI, Masoodi SR, et al. Epidemiologic and etiologic aspects of primary infertility in the Kashmir region of India. Fertil Steril 1997;68(4):637-43.

7. World Health Organization. Reproductive health indicators for global monitoring: report of the second interagency meeting. Geneva: World Health Organization; 2001;p 23.

8. Kanal P, Sharma S. Study of primary infertility in females by diagnosticlaparoscopy. Internet Journal of Medical Update 2006;1(2):7-9.

9. Shireen J, Jejeebhoy. Infertility in India-levels, patterns and consequences: priorities for social science research. Journal of family welfare 1998;44(2):15-24.

10. Adamson PC, Krupp K, Alexandra HF, et al. Prevalence and correlates of primary infertility among young women in Mysore, India. Indian J Med Res 2011;134:4406.

11. Kumar D. Prevalence of female infertility and its socio economic factors in tribal communities of central India. Rural and remote health. Avail from: URL:http://www.rrh.org.au 2007. 
12. Chethana R, Shilpa. Prevalence \& risk factors influencing primary infertility. J of Evolution of Med and Dent Sci 2014;3(13):3384-93.

13. Aflatoonian A, Syed MS, Nasim T. The epidemiological \& etiological aspects of infertility in Yazd province in Iran. Iranian Journal of reproductive Medicine 2009;7(3):11722.

14. Fertility survey in India, Helping Families-Endorsed by ASPIRE and ISAR; supported by Merck Serono. 46\% couples in the age groupof 31-40 are found to be infertile. Mumbai, 2013.
15. Shamila S, Sashikal SL. Primary report on the risk factors affecting female infertility in south Indian districts of Tamil Nadu \& Kerala. Ind J Comm Med 2011;36(1):5961.

16. Anshu Mittal, ShwetaYadav, Sachin Singh Yadav, et al. An epidemiological study of infertility among urban population of ambala, Haryana. International Journal of Interdisciplinary and Multidisciplinary Studies (IJIMS) 2015;2(4):124-130. Available online at http://www.ijims.com ISSN: 2348-0343. 